\title{
Efecto antimicrobiano del extracto crudo oleoso de Rosmarinus Officinalis sobre cepa de Escherichia coli
}

\section{Effect antimicrobial of extract of Rosmarinus officinalis on strain of Escherichia coli}

Montero-Recalde Mayra Andrea*, Martinez-Jimenéz Jorge Aníbal, Avilés-Esquivel Diana Fernanda, Valle-Velástegui Edgar Luciano, Pazmiño-Miranda Nelly Del Pilar

\begin{tabular}{l}
\hline Datos del Artículo \\
\hline Universidad Técnica De Ambato. \\
Facultad De Ciencias Agropecuarias. \\
Cantón Cevallos-Tungurahua-Ecuador. \\
Casilla postal: 18-01-334. \\
Telf: (593) 032746151 - 032746171. \\
jamj 99@yahoo.es \\
df.aviles@uta.edu.ec \\
el.valle@uta.edu.ec \\
nd.pazmino@uta.edu.ec \\
*Dirección de contacto: \\
Mayra Andrea Montero-Recalde \\
Universidad Técnica De Ambato. \\
Facultad De Ciencias Agropecuarias. \\
Cantón Cevallos-Tungurahua-Ecuador. \\
Casilla postal: $18-01-334$. \\
Telf: (593) 032746151 - 032746171. \\
E-mail: ma.montero@uta.edu.ec \\
$\quad \underline{\text { mayrismontero@ @ahoo.es }}$ \\
\hline Palabras clave: \\
\hline Escherichia coli, \\
antibiograma, \\
MacFarland, \\
arrastre de vapor, \\
discos oxoid, \\
destilación. \\
\hline
\end{tabular}

J Selva Andina Biosph. 2017; 5(2):168-175.

\section{Historial del artículo. \\ Recibido marzo, 2017 \\ Devuelto agosto 2017 \\ Aceptado septiembre, 2017. \\ Disponible en línea, noviembre 2017. \\ Editado por: \\ Selva Andina \\ Research Society}

(C) 2017. Journal of the Selva Andina Biosph. Bolivia. Todos los derechos reservados.

El trabajo de investigación tuvo como objetivo evaluar in vitro la eficacia antimicrobiana del extracto oleoso crudo de romero (Rosmarinus officinalis L.) sobre Escherichia coli. Se evaluaron concentraciones al $20 \%, 40 \%$, 60 y $80 \%$ en dilución en etanol al $70 \%$.

Se determinó la CIM mediante el método de microdilución en caldo, el inóculo bacteriano de la cepa ATCC 25922 se activó en el agar diferencial para Enterobacterias MacConkey y se la estandarizó al 0.5 de la escala de MacFarland en espectrofotómetro, teniendo como resultado que el tubo al $60 \%$ y $80 \%$ de extracto oleoso de romero no presentaron turbidez, los cuales al ser sembrados en agar Mueller-Hinton determinó la CMB en la que no se observó crecimiento de colonias.

Se realizó la medición de los halos de inhibición formados a partir de los discos OXOID impregnados con las concentraciones del extracto oleoso de romero más etanol y se concluye que el extracto oleoso al $60 \%$ y $80 \%$ presentaron el mayor efecto antibacteriano al formar halos de $9.10 \mathrm{~mm}$ y $10.90 \mathrm{~mm}$ respectivamente

\section{Abstract}

The objective of the research work was to evaluate in vitro the antimicrobial efficacy of the crude oil extract of rosemary (Rosmarinus officinalis) on Escherichia coli. Concentrations were evaluated at 20\%, 40\%, 60 and $80 \%$ in dilution in $96.8 \%$ ethanol.

The MIC was determined by the broth microdilution method, the bacterial inoculum of the strain ATCC 25922 was activated in the differential agar for MacConkey Enterobacteria and it was standardized to 0.5 of the MacFarland scale in spectrophotometer, having as a result that the $60 \%$ tube and $80 \%$ oil extract of rosemary did not present turbidity, which when planted on Mueller-Hinton agar determined the MBC in which no colony growth was observed.

The measurement of the inhibition rings formed from the OXOID disks impregnated with the concentrations of the rosemary oil extract plus the $70 \%$ ethanol solvent was carried out and it was concluded that the $60 \%$ and $80 \%$ oil extract had the highest antibacterial effect when forming halos of $9.10 \mathrm{~mm}$ and $10.90 \mathrm{~mm}$ respectively.

\section{$\underline{\text { Key words: }}$}

Escherichia coli 


\section{Introducción}

El Estado prevendrá y controlará la introducción y ocurrencia de enfermedades de animales y vegetales, asimismo promoverá prácticas y tecnologías de producción, industrialización, conservación y comercialización que permitan alcanzar y afianzar la inocuidad de los productos. Para tal efecto, el Estado mantendrá campañas de erradicación de plagas y enfermedades en animales y cultivos, fomentando el uso de productos veterinarios y fitosanitarios amigables con el medio ambiente. Los animales que se destinen a la alimentación humana serán reproducidos, alimentados, criados, transportados y faenados en condiciones que preserven su bienestar y la sanidad del alimento (Asamblea Nacional, 2010).

Por esta razón, el uso de fitobióticos, ha despertado el interés para evaluar las propiedades de los extractos de plantas y remplazar el uso de antibióticos, ya que estos crean resistencia bacteriana (Iyobe 1997). Dados los innumerables usos en el ámbito fitoterapéutico, el romero (Rosmarinus officinalis L.) perteneciente a la familia Lamiaceae, es una especie originaria de la región mediterránea, rica fuente de metabolitos activos, muy usada en la medicina tradicional por sus efectos digestivos, antiespasmódicos y carminativos (Castaño et al., 2010). La propiedades antimicrobianas del romero ( $R$. officinalis L.) han presentado interés en el campo alimentario y farmacéutico (Po-Jung et al. 2007), utilizado por sus propiedades como un antimicrobiano natural, a partir de la extracción de sus hojas Mounchid et al. 2005, no obstante el mayor espectro de acción lo presenta el aceite esencial, evidenciándose por los valores bajos de Concentración mínima inhibitoria (CIM) que presenta sobre Escherichia coli y otras de interés alimentario (Castaño et al. 2010).
$\mathrm{Su}$ actividad biocida se define como la capacidad que posee un compuesto natural para inhibir el crecimiento de microorganismos, así se encuentran plantas como el romero ( $R$. officinalis L:) con diferentes bondades y varios efectos como antiinflamatorios, astringentes, antiespasmódicos además del efecto bactericida. El romero contiene más de 40 principios antibacterianos y más de 20 antivíricos, en su composición se encuentran, terpenoides, flavonoides, ácidos fenólicos, pequeñas cantidades de alcaloide rosmaricina y un $2 \%$ de aceite esencial (Estrada-Orozco, 2010).

Con estos antecedentes, este trabajo consiguió determinar la actividad antibacteriana del extracto oleoso de R. officinalis L. sobre Escherichia coli, mediante el uso del extracto crudo oleoso de romero ecuatoriano, aplicando la técnica microbiológica de difusión en disco, para su posible aplicación en animales, ya sea para uso como fármaco o para formulación de dietas balanceadas según los resultados de este estudio.

\section{Materiales y métodos}

Los parámetros de evaluación considerados fueron: CIM, CMB y sensibilidad antimicrobiana mediante la medición de los halos de sensibilidad formados por las concentraciones al 20\%, 40\%, 60\% y $80 \%$ del aceite crudo oleoso de romero.

Obtención de material biológico. La cepa utilizada para el ensayo fue: Escherichia coli ATCC 25922. (Figura 1)

Obtención del extracto de romero. Para la obtención del extracto de romero, se tomó $2 \mathrm{~kg}$ de ramas del arbusto de romero antes de la floración utilizando las hojas más jóvenes, a las cuales se las lavó con 
agua bidestilada y se las dejó secar por 24 h bajo sombra, se procesó con el equipo tipo Clevenger, obteniéndose el extracto mediante el proceso de destilación por arrastre de vapor, esta técnica separa sustancias ligeramente volátiles e insolubles en agua, de otros productos no volátiles mezclados con ellos (Domínguez 2009, Figura 2), posteriormente se sometió a un proceso de decantación para separar el extracto acuoso del oleoso del romero, con el extracto oleoso al $100 \%$, a partir de este se preparó las 4 concentraciones porcentuales, así: al 20\% 4 $\mathrm{mL}$ de etanol $+1 \mathrm{~mL}$ del extracto oleoso de romero, $40 \% 3 \mathrm{~mL}$ de etanol $+2 \mathrm{~mL}$ del extracto oleoso de romero, $60 \% 2 \mathrm{~mL}$ de etanol $+3 \mathrm{~mL}$ del extracto oleoso de romero y finalmente $80 \% 1 \mathrm{~mL}$ de etanol $+4 \mathrm{~mL}$ del extracto oleoso de romero.

Figura 1 Escherichia coli ATCC 25922

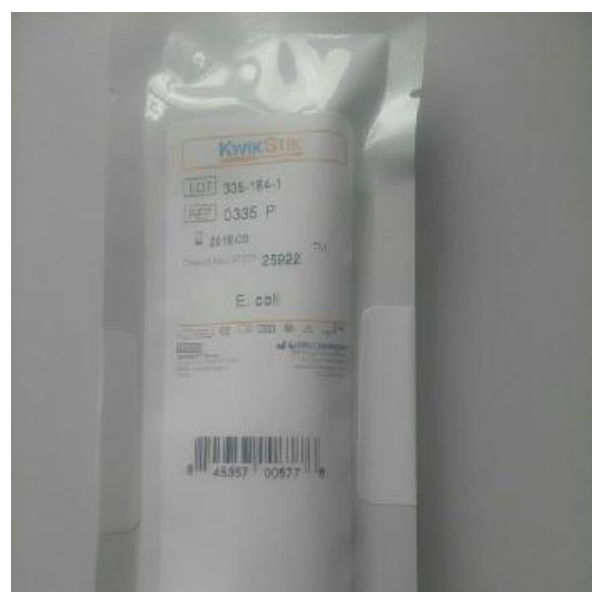

Concentración Mínima Inhibitoria (CIM) del extracto crudo oleoso de Rosmarinus officinalis. Para la determinación de la CIM, se realizó la preparación del inóculo como lo recomienda el National Committee for Clinical Laboratory Standards (NCCLS 2012) para lo cual se tomó con un asa bacteriológica 5 UFC bien aisladas y del mismo tipo morfológico del medio cultivado y se inoculó en 5 $\mathrm{mL}$ de caldo cerebro-corazón, llevando a incubación a $37{ }^{\circ} \mathrm{C}$ por $2 \mathrm{~h}$, hasta obtener una turbidez estandarizada al tubo 0.5 de escala de McFarland para lo cual se observó en un fondo blanco con líneas negras como contraste, teniendo el estándar una concentración establecida de $1.5 \times 10^{8}$ de UFC.

Figura 2 Equipo tipo Clevenger

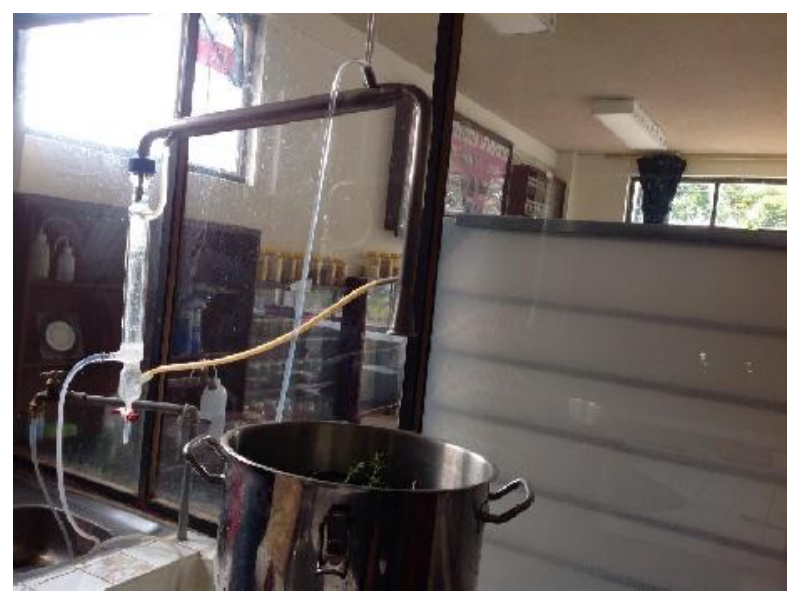

Tabla 1 Concentración mínima inhibitoria

\begin{tabular}{cc}
\hline Tubo & Inóculo más extracto de romero \\
\hline Número 1 & $1 \mathrm{~mL}$ del inóculo más $1 \mathrm{~mL}$ del extracto de romero al 20\% \\
Número 2 & $1 \mathrm{~mL}$ del inóculo más $1 \mathrm{~mL}$ del extracto de romero al $40 \%$ \\
Número 3 & $1 \mathrm{~mL}$ del inóculo más $1 \mathrm{~mL}$ del extracto de romero al 60\% \\
Número 4 & $1 \mathrm{~mL}$ del inóculo más $1 \mathrm{~mL}$ del extracto de romero al $80 \%$ \\
\hline
\end{tabular}


La técnica se aplicó en base a el National Committee for Clinical Laboratory Standards, tomando a partir del inóculo estandarizado $4 \mathrm{~mL}$ para la determinación de la CIM especificado en la tabla 1.

Los tubos inoculados se llevaron a incubación a una temperatura de $37^{\circ} \mathrm{C}$ por $24 \mathrm{~h}$ y posterior a este tiempo, se observó la turbidez a las concentraciones analizadas y el tubo con menor turbidez se lo determinó como la CIM, siendo el tubo número 4 con extracto al $80 \%$ como la concentración mínima que impide el crecimiento de microorganismos. NCCLS 2011, NCCLS 2012.

Determinación de la Concentración Mínima Bactericida $(C M B)$. Para establecer la $\mathrm{CMB}$, se eligió los tubos que presentaron menor turbidez en la determinación de la CIM y se sembró en agar MacConkey incubándose a $37^{\circ} \mathrm{C}$ por $24 \mathrm{~h}$. NCCLS 2012, NCCLS 2011 comprobando el cero crecimiento de UFC en placa tanto al $60 \%$ y $80 \%$ del extracto crudo oleoso de romero. Figura 3.

\section{Figura 3 Concentración mínima inhibitoria}

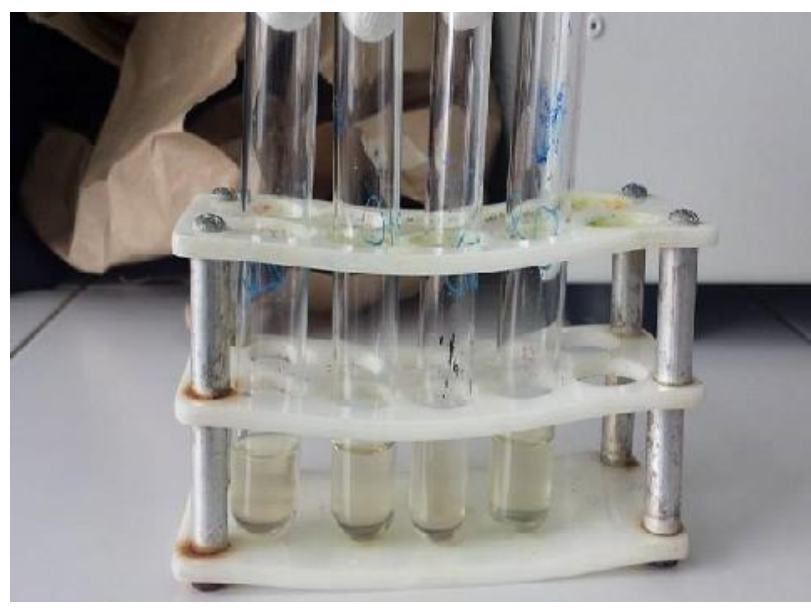

Sensibilidad antibacteriana. Se tomó con un hisopo estéril el inóculo preparado y estandarizado con el tubo número 5 de la escala McFarland, y al retirarlo se tuvo precaución de escurrir el hisopo sobre las paredes del tubo retirando el exceso de líquido.

\section{Figura 4 Escherichia coli cultivada en agar MacConkey}

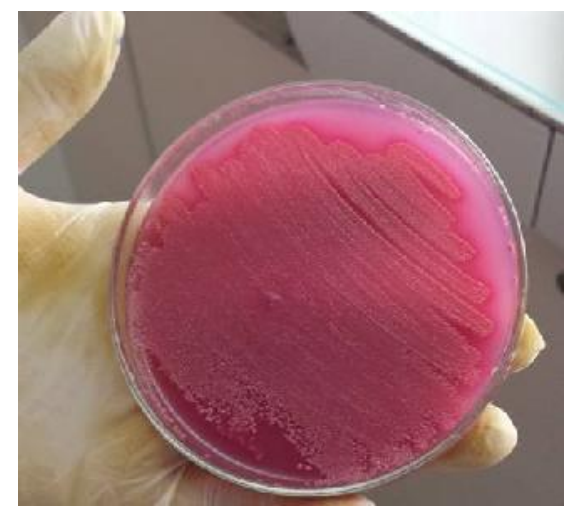

Figura 5 Discos impregnados con las concentraciones del aceite de romero

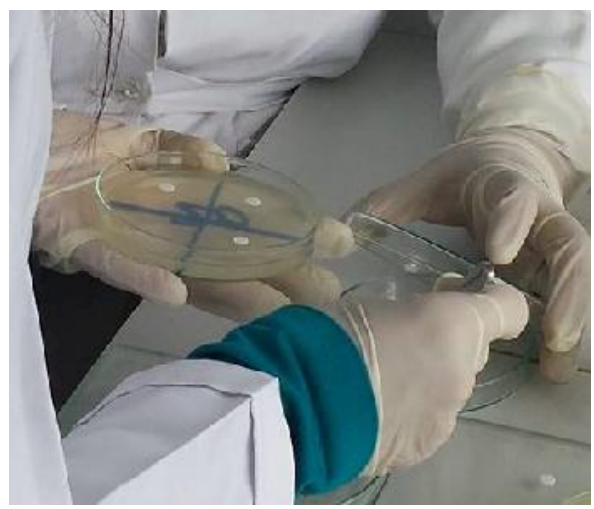

Figura 6 Placas e incubando a $37^{\circ} \mathrm{C}$

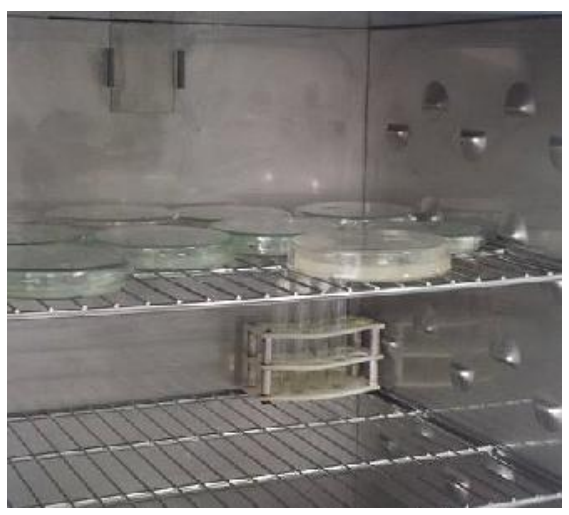


Se preparó el inóculo de la siguiente manera: se tomó con aza bacteriológica cinco colonias de la cepa de Escherichia coli cultivada previamente por 24 h en agar MacConkey Figura 4, se inocularon en $5 \mathrm{~mL}$ de caldo Cerebro-Corazón he incubaron a 37 ${ }^{\circ} \mathrm{C}$ durante $3 \mathrm{~h}$ hasta que se desarrolló turbidez semejante al tubo $\mathrm{N}^{\circ} 0.5$ de la escala de MacFarland a una concentración de 1x $10^{-8}$ UFC. Posteriormente se procedió a cultivar con ayuda de un hisopo estéril por estriado múltiple en agar Mueller Hinton, dejando reposar por $10 \mathrm{~min}$ antes de colocar los discos de sensibilidad OXOID impregnados con las dosis del extracto crudo oleoso de romero y etanol al $70 \%$ como testigo y se los dejó secar 5 min antes de colocar los discos. Se ubicaron los discos impregnados con las concentraciones del aceite de romero y se las ubicó con una pinza anatómica estéril sobre el Agar Mueller Hinton y se los presionó suavemente para permitir su adherencia al agar de manera apropiada en la placa a $15 \mathrm{~mm}$ del borde de la misma, se utilizaron cajas Petri de $90 \mathrm{~mm}$ y se ubicaron 4 discos impregnados del extracto crudo oleoso de rome- ro en cada placa, con 4 repeticiones por placa por cada una de las concentraciones al 20\%, 40\%, 60\% y $80 \%$ Figura 5, distribuidos de forma que no se produjo superposición de los halos de inhibición ubicando los discos en las placas e incubando a 37 ${ }^{\circ} \mathrm{C}$ en grupos no mayores a diez placas durante $24 \mathrm{~h}$ completas y de manera invertida Figura 6. Posteriormente se procedió a realizar la lectura de los discos y se lo hizo a través de la medición de los halos de inhibición con una regleta de medición en milímetros. NCCLS 2011, NCCLS 2012.

\section{Resultados}

El comportamiento de la cepa Escherichia coli ATCC 25922 TM* frente al incremento en las concentraciones de extracto crudo oleosos de romero, presenta actividad en la turbidez de cada una de las muestras realizadas (Tabla 2), exponiendo así, que desde el $1 \%$ en adelante no presenta turbidez y por tanto no existe crecimiento bacteriano.

Tabla 2 Determinación de la concentración mínima inhibitoria (CIM) del extracto crudo oleoso de Romero (Rosmarinus officinalis)

\begin{tabular}{lcccc}
\hline & \multicolumn{3}{c}{ Concentraciones de aceite de romero } & Control negativo Etanol al 96.8 \\
\cline { 2 - 5 } Cepa & $20 \%$ & $40 \%$ & $60 \%$ & $80 \%$ \\
\hline Escherichia coli ATCC 25922 TM* & + & Crecimiento & + \\
\hline Positivo (+), Negativo (-) & + & - & - \\
\hline
\end{tabular}

Tabla 3 Determinación de la concentración bactericida mínima (CMB) del aceite esencial de Romero (Rosmarinus officinalis)

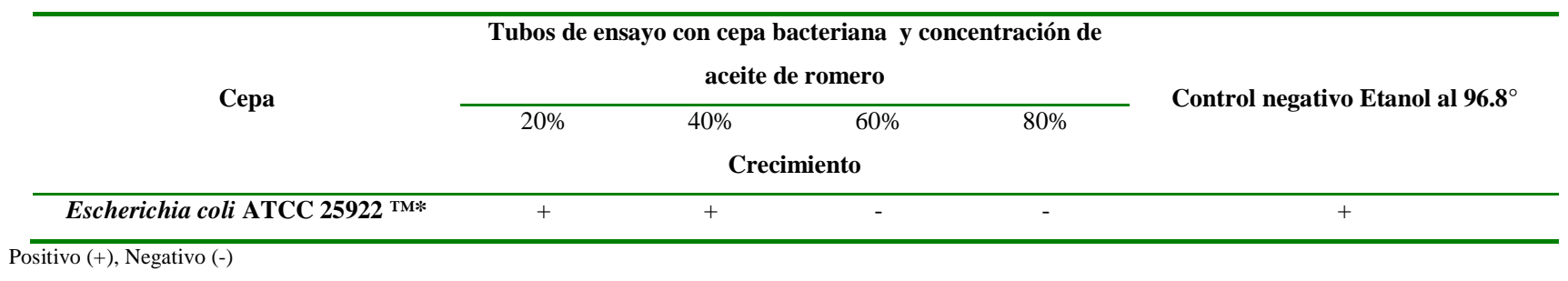


Tabla 4 Halos de sensibilidad (mm) del extracto crudo oleoso de Romero (Rosmarinus officinalis)

\begin{tabular}{|c|c|c|c|c|c|c|c|c|}
\hline Concentraciónón & Testigo & $20 \%$ & $40 \%$ & $60 \%$ & $80 \%$ & C.V & E.E & P. Valor \\
\hline Escherichia coli ATCC 25922 TM* & $0.0 \mathrm{~d}$ & $5.55 \mathrm{c}$ & $6.80 \mathrm{bc}$ & $9.10 \mathrm{ab}$ & $10.90^{\mathrm{a}}$ & 10.11 & 0.12 & $<0.0001$ \\
\hline
\end{tabular}

Con respecto a la CBM no se apreció crecimiento de colonias en agar Mueller Hinton (tabla 3), por lo tanto las concentraciones de aceite de romero al $60 \%$ y $80 \%$ no permitieron el desarrollo bacteriano de la cepa de Escherichia coli ATCC 25922 TM* Con respecto a la CBM no se apreció crecimiento de colonias en agar Mueller Hinton (tabla 4), por lo tanto las concentraciones de aceite de romero al $60 \%$ y $80 \%$ no permitieron el desarrollo bacteriano de la cepa de Escherichia coli ATCC 25922 TM*

\section{Discusión}

El extracto de romero cuenta de manera clara con compuestos activos de efectos antimicrobianos sobre bacterias de contaminación alimentaria, además se los puede utilizar como alternativa natural de tipo conservante evitando así el riesgo toxicológico por el uso de conservantes sintéticos (Castaño et al. 2010).

El extracto de romero utilizado para el desarrollo de esta investigación, fue de tipo oleoso y mostró resultados positivos al inhibir el crecimiento de Escherichia coli ATCC 25922 in vitro, a una concentración del $80 \%$, formando halos de inhibición bacteriano de $10.90 \mathrm{~mm}$, al igual que (Solano-Solano et al. 2016) concluye en su tesis de pregrado que el extracto oleoso determinó halos de inhibición de $11.93 \mathrm{~mm}$ sobre la cepa certificada de Streptococcus mutans. Lanas-Terán \& Marín-Vega 2016 en su investigación manifiesta que el extracto acuoso de romero aplicado al $100 \%$ en una cepa de $S$. mutans no mostró un halo mayor a $6.15 \mathrm{~mm}$, al contrario el autor refiere que el extracto de romero más extracto de salvia mostró un halo de inhibición de $12.60 \mathrm{~mm}$; mientras que el resultado de ésta investigación que se desarrolló a partir del extracto de romero sin combinación con otra materia vegetal, aplicado en la cepa de Escherichia coli ATCC 25922, si mostró actividad antimicrobiana al $80 \%$ de concentración, determinándose halos de inhibición de $10.90 \mathrm{~mm}$ a las 24 h de incubación a $37^{\circ} \mathrm{C}$.

La dimensión de los halos de inhibición con la concentración al $80 \%$ de extracto de romero fue de $(10.90 \mathrm{~mm})$, resultados similares los evidencia Solano-Solano et al. (2016) indicando que el extracto oleoso de romero produjo una media de $11.93 \mathrm{~mm}$ de halo de inhibición ( $\mathrm{p}<0.001)$, diferencia significativa al grupo control, además mostrando similitud con el efecto de la clorhexidina.

Los extractos acuosos de Salvia con Romero al $100 \%$ de concentración sobre el S. mutans, mostraron un halo de inhibición de $12.60 \mathrm{~mm}$ a las $24 \mathrm{~h}$ y de $15.40 \mathrm{~mm}$ a las $48 \mathrm{~h}$, mientras que la acción bactericida del extracto acuoso de Salvia (Salvia Officinalis) al $100 \%$, sobre el S. mutans, mostró un halo de inhibición de $12.45 \mathrm{~mm}$ a las $24 \mathrm{~h}$ y de $15.35 \mathrm{~mm}$ a las 48 h Lanas-Terán \& Marín-Vega 2016. El extracto de romero ( $R$. officinalis) utilizado en la presente investigación a la concentración de $60 \%$ mostró resultados similares con halos de inhibición de $9.10 \mathrm{~mm}$ a las $24 \mathrm{~h}$ de incubación, mientras que a la concentración de $80 \%$ los halos de inhibición fueron de $10.90 \mathrm{~mm}$ a las $24 \mathrm{~h}$ de incubación, siendo esta la concentración del extracto que no permitió que la bacteria se desarrolle. 
El extracto oleoso de Rosmarinus officinalis mantiene una relación directa entre la concentración de extracto y su efecto antibacteriano.

\section{Conflictos de intereses}

La investigación realizada no presenta conflictos de interés.

\section{Agradecimientos}

Los autores agradecen a la Universidad Técnica de Ambato Facultad de Ciencias Agropecuarias, por el apoyo técnico, científico y logístico realizado a la presente investigación.

\section{Literatura citada}

Asamblea Nacional. Ley Organica del Regimen de la Soberania Alimentaria. Fernando Cordero Cueva, Francisco Vergara; 2010. p. 13.

Botana-López LM, Landoni MF, Martín-Jimé nez T. Farmacología y Terapéutica Veteri naria (1st ed.). Madrid: Mcgraw Hill Inter americana; 2002. p. 713.

Castaño HI, Ciro G, Zapata JE, Jimènez SL. Actividad bactericida del extracto etano lico y del aceite esencial de hojas de Ros marinus officinalis L. sobre algunas bacte rias de interes alimentario. Vitae 2010; 17(2):149-54.

Dominguez $X$. Destilacion por arrastre de vapor, caracteristicas, ventajas y aplicacio nes. In Química orgánica. 2009.
Estrada-Orozco SP. Determinación de la actividad antibacteriana in vitro de los extractos romero (Rosmarinus officinalis) y tomillo (Thymus vulgaris). [Tesis de Licenciatura], Escuela Superior Politécnica de Chimborazo. Riobamba, Ecuador; 2010. p.86.

Iyobe S. Appearance of extended spectrum beta Lactamases. J Nipón Riwsho 1997;55(5): 1219-24.

Lanas-Terán GA, Marín-Vega GX. Efectividad del extracto acuoso de salvia, romero y de salvia-romero al $100 \%$ como bactericida sobre el Streptococcus mutans. Estudio microbiológico in vitro. [tesis licenciatura]. Universidad Central del Ecuador; 2016. p. 76.

Mounchid K, Bourjilat F, Dersi N, Aboussaouira T, Rachidai A, Tantaoui-Elaraki A et al. The susceptibility of Escherichia coli strains to essential oils of Rormarinus officinal and Eucalyptus globulus. Afr J Biotechnol. 2005;4(10):1175-6.

National Committee for Clinical Laboratory Standards. Performance Standards for Antimicrobial Susceptibility Testing; TwentyFirst Informational Supplement. 2011; 31(1):1-172.

National Committee for Clinical Laboratory Standards. Performance standards for antimicrobial disk susceptibility tests, approved standard. 11th Edition. 2012; 32(1): $1-32$.

Po-Jung T, Tzung-Hsun T, Su-Chen H. In vitro inhibitory effects of rosemary extracts on 
rowth and glucosyltransferase activity of Streptococcus sobrinus. Food Chem. 2007; 105(1): 311-6.
Solano-Solano XK, Tamara Jacqueline MoyaSilva TJ, María Isabel Zambrano-Gutiérrez MI. Inhibición del Streptococcus mutans, mediante el uso de extracto acuoso y oleoso de Rosmarinus officinalis "romero". Odontología. 2016;19(2):29-34. 